\title{
As contradições da promoção à saúde em relação à produção de sujeitos e a mudança social
}

\author{
Health promotion contradictions regarding \\ the issues of the subject and the social change
}

Sérgio Resende Carvalho 1

${ }_{1}$ Departamento

de Medicina Preventiva e Social da Faculdade de Ciências Médicas, Unicamp.

Cidade Universitária

Zeferino Vaz, 13081-970, Campinas SP.

srcarvalho@terra.com.br
Abstract The objective of this exploratory study is to analyze conceptual theoretical model of Health Promotion, reflecting on this project's position regarding the issues of health production, the subjects and the social changes. Having the Canadian proposal as a reference, I describe the conceptual development of Health Promotion. After pointing out the ambiguities of this, this paper aims to reflect about two of the main categories for the New Health Promotion/New Public Health, which are: risk and empowerment. I conclude about the necessity of cautiousness when incorporating the principals and strategies Promotion the Brazilian Unified Health System (SUS), since these may "mean everything to everyone and thus may serve as compromised propositions to the status quo and, as a paradox, to projects of change. To consolidate the last tendency, I suggest that it is fundamental for the Brazilian reality to reaffirm "health as a right and a State duty", recommending as path to an effective and "healthy" Health Promotion the concept use of "community empowerment".

Key words Autonomy, Health quality, Public health, Health promotion, Risk
Resumo Realizo um estudo que tem como objetivo analisar o modelo teórico-conceitual da promoção à saúde - e nela a formulação canadense buscando refletir sobre o posicionamento desse projeto em relação aos temas da produção da saúde, do sujeito e da mudança social. Após assinalar a pluralidade de opiniões encontráveis na literatura sobre promoção, o trabalho discute o significado e as conseqüencias do uso das categorias "risco" e "empowerment" junto com a Nova Promoção à Saúde/Nova Saúde Pública. Concluo pela necessidade de cautela na incorporação dos princípios e estratégias de promoção à saúde ao SUS uma vez que eles podem "significar tudo para todos" e, exatamente por isso, podem servir a proposições comprometidas com o status quo $e$, paradoxalmente, a projetos socialmente transformadores. Para que a última tendência se consolide, sugiro ser fundamental para a realidade brasileira reafirmar "a saúde como um direito e um dever do Estado", propondo como caminho para a efetivação de uma Promoção à Saúde "Saudável" a utilização do conceito de "empowerment comunitário".

Palavras-chave Autonomia, Qualidade de vida, Saúde pública, Promoção à saúde 


\section{Introdução}

Os novos desafios sociais, políticos e culturais, o esgotamento do paradigma biomédico e a mudança do perfil epidemiológico da população nas últimas décadas têm ensejado o aparecimento de novas formulações sobre o pensar e o fazer sanitários. Entre essas sobressai o projeto da Promoção à Saúde que constitui hoje o eixo principal do projeto da Nova Saúde Pública.

Sob o patrocínio da Organização Mundial da Saúde o ideário da Promoção à Saúde vem, desde suas origens nos anos 70, tendo uma crescente influência nas políticas públicas de distintos países. No Brasil ela se faz presente na proposta da Vigilância à Saúde (Mendes, 1993; Teixeira et al., 1998), sustenta o projeto de Cidades Saudáveis (Westfall, 2000), influencia práticas de Educação à Saúde (Hills, 2000) e, não menos importante, suas diretrizes são partes estruturantes de muitos dos projetos de reorganização da rede básica hoje vinculados ao Programa Saúde da Família.

Tomando como base a formulação canadense da promoção à saúde, descrevo neste trabalho o desenvolvimento histórico conceitual deste projeto para, a seguir, refletir sobre os seus aportes e limitações para se pensar a mudança e a produção de sujeitos/cidadãos no Sistema Único de Saúde.

\section{Momento 1 \\ Os primórdios da promoção à saúde no Canadá (1974-1986)}

O Movimento de Promoção à Saúde no Canadá desenvolve-se a partir da divulgação do relatório de discussão denominado The new perspective for the Health of Canadians, que se tornou conhecido como Relatório Lalonde.

O relatório preconiza que as ações de saúde devam ter como objetivos adicionar anos à vida e adicionar vida aos anos, ou seja, garantir a qualidade de vida de indivíduos e coletivos. Conceito importante que se faz presente é o de campo de saúde - um conjunto de práticas e saberes que influenciam a saúde e que extrapolam os serviços de saúde -, que subsidia a proposta de modelo explicativo em saúde, uma espécie de mapa do território em que é realçado o papel de quatro grupos na determinação do processo saúde-doença: biologia humana (genética e função humana), organização dos serviços de saúde; ambiente (natural e social) e es- tilo de vida (comportamento individual que afeta a saúde).

Partindo do diagnóstico de que a visão tradicional de igualar o nível de saúde no Canadá com a disponibilidade de médicos e hospitais é inadequada, o Relatório recomenda a mudança no foco das ações sanitárias ao afirmar que não há dúvidas de que futuros aprimoramentos no nível de saúde dos canadenses dependem, principalmente, da melhoria de meio ambiente, da moderação de comportamentos de riscos e da ampliação do conhecimento sobre a biologia humana (Lalonde, 1974). Tomando como pressuposto que os indivíduos devam assumir a responsabilidade sobre os efeitos deletérios de seus hábitos de vida - um agregado de decisões individuais que afetam a saúde - não saudáveis, esta abordagem sugere um conjunto de intervenções sobre os estilos de vida que enfatizam, inicialmente, áreas-problemas como o tabagismo, o alcoolismo, as drogas e os hábitos alimentares (Lalonde, 1974).

Investigações da década de 1990 constatam que as estratégias derivadas dessa abordagem foram responsáveis pela melhoria da qualidade de vida de alguns grupos sociais mostrando que os resultados, em termos de qualidade de vida, variaram de acordo com a extração social do indivíduo. Constata-se um melhor aproveitamento por setores mais bem situados na escala social e um efeito menor, e até mesmo negativo, por parte de setores marginalizados (Hyndman, 1998).

Este fenômeno foi objeto de análise de inúmeros estudiosos que apontam, como uma debilidade do modelo explicativo da promoção à saúde, a incorporação residual de fatores como classe, gênero e raça e a excessiva ênfase em intervenções behavioristas. Deriva daqui o conceito de "culpabilização das vítimas" (blaming the victims) pelo qual os investigadores significam a situação em que grupos populacionais à margem do desenvolvimento capitalista são responsabilizados por problemas de saúde cujas causas encontram-se fora de sua governabilidade (Crawford, 1977; Labonte \& Penfold, 1981; Labonte, 1993).

\section{Momento 2 \\ A promoção à saúde na sua adolescência: novos sonhos, antigas realidades?}

Em meados da década de 1980 tornou-se necessário a atualização do Movimento de Pro- 
moção à Saúde visando superar os limites teóricos e práticas do projeto behaviorista. Em linha de continuidade com Alma Ata (Baum \& Sanders, 1995) é formulada a vertente socioambiental também denominada de Nova Promoção à Saúde (Robertson \& Minkler, 1994).

Documento pioneiro dessa abordagem foi o "relatório de trabalho" da OMS/Europa de 1984 em que se preconiza, entre outros, que a promoção à saúde deva ter um papel na transformação das condições de vida dos mais desfavorecidos e que deva favorecer a participação dos indivíduos e de grupos populacionais em processos decisórios que digam respeito a ações de saúde (WHO, 1984). No mesmo ano, realiza-se na cidade de Toronto, no Canadá, a Conferência Beyond Health Care, que lança as bases do projeto de Políticas Públicas Saudáveis (Hancock, 1985).

A Carta de Ottawa sintetiza essa produção que foi, posteriormente, detalhada em inúmeros documentos de instituições canadenses e internacionais. Pela importância política e pelo papel na divulgação deste ideário cabe destacar as cinco Conferências Internacionais de Promoção à Saúde que a OMS patrocinou no período de 1986 e 2000.

A abordagem socio-ambiental passa a definir promoção à saúde como o processo de capacitação (enabling) de indivíduos e coletivos (communities) para que tenham controle sobre os determinantes de saúde com o objetivo de terem uma melhor qualidade de vida. Esta categoria constitui um conceito que sintetiza dois elementos-chave para a promoção: a necessidade de mudanças no modo de vida e, também, das condições de vida. Representa, igualmente, uma estratégia de mediação entre as pessoas e o meio ambiente, combinando escolhas pessoais com responsabilidade social com o objetivo de criar um futuro mais saudável.

Para que os indivíduos ou o coletivo tenham saúde, a Carta julga necessário que sejam capazes de identificar e realizar aspirações, satisfazer necessidades e transformar, ou adaptar-se, de acordo com o meio. Recomenda a superação da iniqüidade na saúde, propondo ações que tenham como objetivo garantir oportunidades e recursos para possibilitar que as pessoas alcancem o máximo de saúde e que tenham competência para fazer as escolhas saudáveis. Às mencionadas estratégias, a Nova Promoção à Saúde acrescenta a "criação de ambientes sustentáveis", a "reorientação dos serviços de saúde", o "desenvolvimento da capacida- de dos sujeitos individuais" e o "fortalecimento de ações comunitárias” (WHO, 1986).

A seguir procuro refletir sobre as premissas e estratégias apontadas mencionando, como ponto de partida, a opinião de alguns estudiosos brasileiros sobre a Promoção à Saúde.

\section{A multiplicidade de olhares sobre a promoção à saúde}

Ao revisar publicações sobre a promoção à saúde em revistas como o Canadian Public Health Journal, International Health Promotion, Ciência \& Saúde Coletiva e Cadernos de Saúde Pública, documentos da Organização Mundial da Saúde e artigos de consagrados pesquisadores, detecto a existência de uma miríade de opiniões sobre a promoção à saúde.

Para o que nos interessa julgo de utilidade registrar dois posicionamentos centrais. O primeiro tende a afirmar o caráter progressista da Nova Promoção à Saúde, considerando que esse projeto representa um esforço de atualização dos compromissos com o bem comum, a eqüidade social e os princípios democráticos da "tradição" da Saúde Pública (Carvalho, 1996). Este modo de ver é compartilhado, por exemplo, por Buss quando considera que a promoção à saúde procura articular o tema da saúde com os temas da condição e qualidade de vida afirmando que este ideário representa uma estratégia promissora para enfrentar os múltiplos problemas de saúde que afetam as populações humanas e seus entornos, estando associada a valores como qualidade de vida, saúde, solidariedade, eqüidade, democracia, cidadania, desenvolvimento, participação e parceria, entre outros (Buss, 2000).

O segundo grupo de opiniões é representado por autores que, sem deixar de reconhecer contribuições pontuais deste projeto, consideram que os discursos da promoção da saúde e da evitação de riscos parecem implicitamente refletir a ótica das formações neoliberais, individualistas, que gera grupos de indivíduos entregues a si próprios e à preocupação com o desempenho baseado em condições individuais ... que sustentem uma identidade frágil, povoada cada vez mais por um imaginário composto por elementos vinculados a "questões de saúde" (Castiel, 2003).

Visões tão díspares expressam uma particularidade marcante da Nova Saúde Pública e, nela, da (Nova) Promoção à Saúde: o caráter ambíguo de suas premissas e estratégias. Com 
o intuito de ilustrar as diferentes possibilidades interpretativas em relação ao objeto em estudo, apresento um "mapa de questões" (Quadro 1) que procura indagar sobre o real significado das estratégias de Políticas Públicas Saudáveis e as que almejam o Desenvolvimento de Habilidades Pessoais.

Sem a pretensão de esgotar as respostas possíveis apresento a seguir algumas interpretações, realizando para isto uma análise do significado e conseqüência da utilização das categorias "risco" e empowerment no modelo teóricoconceitual da Nova Saúde Pública / Nova Promoção à Saúde.

\section{Uma breve introdução ao conceito de risco}

$\mathrm{Na}$ abordagem técnico-científica dominante denominada por Lupton (1999) de realista risco é definido como um produto/conseqüência da possibilidade de eventos adversos; como um fator, naturalmente preexistente, passível de ser identificado por intermédio de cálculo e medidas científicas. Ao definir risco como uma forma presente de descrever o futuro sob o pressuposto que se pode decidir qual o futuro desejá$v e l$, Castiel chama a atenção para o fato de que esse conceito iguala as contradições no presente no momento em que estabelece que só se pode administrar o risco (o futuro) de modo racional, ou seja, através da consideração criteriosa da probabilidade de ganhos e perdas, conforme decisões tomadas (Castiel, 2003).

Para Almeida Filho \& Rouquayrol (1992) o risco é um conceito estruturante da epidemiologia moderna, definido como a probabilidade de os membros de uma determinada população desenvolverem uma dada doença ou evento relacionado à saúde em um período de tempo, tendo o cuidado de observarem que, neste caso a probabilidade se refere a modelos abstratos de distribuição populacional, não redutíveis às chances de um indivíduo particular diante de um diagnóstico ou prognóstico. Des-

\section{Quadro 1}

Questões sobre a Nova Promoção à Saúde.

Estratégia Questões / Problemas

Constituir políticas públicas saudáveis

- Colocar a saúde na agenda dos políticos e dos decisores

- Fazer das escolhas saudáveis as escolhas mais fáceis

\section{Desenvolver habilidades pessoais}

- Apoiar/possibilitar/facilitar/ (enable) que pessoas aprendam com a vida e prepará-las para o enfrentamento de distintos desafios e possibilidades.

- Desenvolver habilidades de pessoas, famílias, grupos, organizações, capacitando-os para a análise e para a ação.
Como as Políticas Públicas Saudáveis incorporam o tema do conflito social e da luta reivindicatória dos movimentos sociais?

As Políticas Públicas Saudáveis priorizam estilos de vida saudáveis ou condições de vida e de trabalho saudáveis?

A escolha torna-se mais fácil pelas condições sociais em que o sujeito se insere ou por sua adaptação a imperativos de ordem externa (e.g. equilíbrio fiscal, pagamento de dívida externa)?

Como evitar uma "reengenharia social", ou seja, que a escolha correta seja determinada pelo pensamento tecnocrático e pelos interesses de grupos em posição de poder no Estado? Quem faz a escolha saudável?

Qual o significado da palavra enable?

Qual a concepção de educação em saúde que predomina? Como ocorre o intercâmbio de saberes entre profissionais e usuários? Por uma co-gestão de contratos e compromissos ou por uma relação vertical e autoritária?

A relação profissional / usuário é uma relação de co-produção de sujeitos ou uma relação paternalista? Os usuários são vozes passivas ou ativas? 
te conceito surge a noção correlata de fator de risco, que pode ser definido como um atributo de um grupo que apresenta maior incidência de uma dada patologia, em comparação com outros grupos populacionais, definidos pela ausência ou menor dosagem de tal característica (1992).

É útil observar, como o faz Petersen (1997), que por trás do conceito de risco encontra-se um raciocínio evolutivo pautado pela fé na racionalidade humanista pós-iluminista e pela adesão às idéias de progresso científico e social. Este fato explica que as estratégias voltadas para mudanças sociais, ambientais e sobre estilos de vida em resposta aos riscos individuais e sociais presentes na promoção à saúde aparentem, muitas vezes, representar saltos científicos e técnicos em relação às regras de higiene que se seguiram às descobertas dos microorganismos e dos contaminantes ambientais.

O conceito de risco é estruturante, também, do ideário da promoção à saúde contemporânea subsidiando, entre outras, estratégias como as Políticas Públicas Saudáveis e múltiplas ações que têm como objetivo contribuir para as escolhas de hábitos de vida saudáveis. A crescente atenção à forma física, aos exercícios e dietas constitui a manifestação mais óbvia desse ideário (foco no estilo de vida), acrescida por uma "nova consciência" sobre riscos resultantes da atividade humana (poluição, aquecimento global, biodiversidade, etc.).

Por intermédio das mencionadas estratégias, a promoção à saúde procura responder ao surgimento de um novo complexo mórbido onde causa e efeitos se confundem e se sintetizam num "certo modo de andar a vida", onde fatores como alimentação, stress, poluição, violência e sedentarismo apresentam-se como ingredientes indissociáveis dos marcos culturais e sociais onde se inscrevem (Carvalho, 1996). Mais do que fatores de risco, a promoção à saúde é chamada a tratar de situações complexas onde o risco não é mais externo ao indivíduo mas se inscreve, com ele, num complexo único de múltiplas dimensões - biológica, social e cultural.

A inegável contribuição do conceito de risco para a eficácia das ações sanitárias - tanto na epidemiologia quanto na promoção à saúde - não deve nos desobrigar de uma análise mais criteriosa deste conceito, tendo em vista esclarecer ambigüidades e amadurecer estratégias que tenham como objetivo a defesa da vida individual e coletiva. Neste sentido passo a refletir, a seguir, sobre o significado desta categoria e as conseqüências de sua utilização na promoção à saúde. Privilegio para isto uma perspectiva que enfatiza, no seu olhar, aquilo que é negligenciado na formulação dominante: o risco como uma categoria socialmente construída cujo significado responde à ação de sujeitos que disputam seus interesses. No interior da abordagem construcionista (Lupton, 1999) privilegio o "diálogo" com os "teóricos foucaultianos" por compreendê-los como portadores de um ferramental teórico de especial interesse para a análise da produção de sujeito e da transformação das relações sociais.

Risco, como qualquer outro conhecimento, traduz valores em disputa, não sendo, portanto, um fenômeno estático e objetivo, mas constantemente construído e negociado como parte de uma rede de interações sociais e de construção de sentidos. A definição e a priorização de riscos por parte de "expertos" não são neutras e objetivas como costuma ser retratado na literatura científica, pois são, à semelhança do julgamento dos leigos, construídas através de processos sociais e culturais implícitos. Nada constitui um risco por si mesmo, já que o que nós entendemos como um risco é um produto contingente de "modos de olhar" (Lupton, 1999).

Este entendimento permite avançar questões importantes para uma melhor compreensão da categoria "risco" e de suas conseqüências para as ações de Nova Promoção à Saúde, quais sejam: Como risco é entendido em diferentes contextos sociais? Por que alguns perigos são selecionados como risco e outros não? Como os discursos e práticas que se dão em torno do risco operam a construção da subjetividade e da vida social? As respostas a estas indagações nos ajudam, por exemplo, a esclarecer sobre a gênese do conceito de "hábitos de vida saudáveis" e o modo como ele se manifesta em situações concretas da vida social.

No que se segue procuro dialogar com as mencionadas questões caracterizando, inicialmente, a relação entre risco e a Nova Promoção à Saúde para, na sequência, analisar algumas facetas dessa vinculação.

\section{Promoção à saúde, risco e o controle do social}

A emergência da Nova Saúde Pública sinaliza uma considerável ampliação do campo de ação da promoção à saúde. Em nome da erradicação absoluta dos riscos, o ambiente é esquadrinha- 
do nas suas dimensões físicas, psíquicas e sociais multiplicando, conseqüentemente, os objetos a serem medidos, monitorados e regulados. Sob a base do cálculo da probabilidade ampliase o leque de intervenções e prescrições que passam a ser deduzidas e justificadas a partir do fato de que para ser suspeita a pessoa não necessita manifestar sintomas de perigo ou anormalidade mas, simplesmente, possuir a característica que os expertos responsáveis pelas políticas de prevenção classificam como "fator de risco".

Petersen (1997) chama a atenção para a ocorrência, neste processo, de uma espécie de dissolução das fronteiras entre os saudáveis e não saudáveis uma vez que todas as coisas passam a ser fontes potenciais de risco e todos podem ser vistos como "em risco". Dessa forma, tanto o doente quanto o indivíduo sadio são abarcados nessa rede de observação, em que os expertos cumprem papel central no momento em que desenvolvem normas quantitativas de classificação que produzem, de passagem, identidades.

Nesse arcabouço o saber médico, científico, epidemiológico e social é rotineiramente empregado como a "verdade" para construir "problemas" públicos de saúde e para encontrar a solução para os mesmos (Petersen \& Lupton, 1996). À (Nova) Saúde Pública e a seus técnicos caberia, por exemplo, realizar a descrição e mapeamento da vida social (em forma de relatórios, estatísticas e gráficos) com o objetivo de circunscrever o real e facilitar a gestão e o governo do social.

Por meio da elaboração de regras sobre o viver saudável estes saberes e seus expertos podem contribuir, muitas vezes, para uma forma sutil de vigilância e de regulação do social em que ocorre um deslocamento de estratégia de coerção - realizada diretamente sobre o indivíduo ou por intermédio de técnicas de segregação - para estratégias baseadas no cálculo abstrato dos riscos, que visa antecipar e prevenir a emergência de eventos como a doença e comportamentos desviantes e anormais.

Por caminhos semelhantes virtualmente todas as facetas da vida passam a ser afetadas pelas políticas governamentais que procuram $\mathrm{fa}$ cilitar as opções saudáveis e dificultar as escolhas que trazem dano à saúde individual e coletiva. Dessa maneira tecnologias de promoção podem contribuir para a regulação do corpo biossocial e para o fortalecimento da hegemonia neoliberal (Castel, 1991), em conformidade com Guattari quando este afirma que o capitalismo atual produz indivíduos normalizados e submissos, articulados uns aos outros segundo sistemas hierárquicos e de valores. (...) Estes sistemas produzem uma subjetividade no nível do indivíduo e dos coletivos que pode alcançar todos os niveis da produção e do consumo (...), essa grande fábrica, essa grande máquina capitalística produz inclusive aquilo que acontece conosco quando sonhamos, quando devaneamos, quando fantasiamos, quando nos apaixonamos (Guattari \& Rolnik, 1986).

Para Lupton a subjetividade que a Nova Promoção à Saúde induz é baseada na imagem de um indivíduo de classe média, racional, civilizado, disciplinado e consciente de sua saúde. Uma subjetividade na qual a ênfase na escolha individual e na auto-determinação como um afastamento radical do modelo biomédico de prevenção pode ser mais aparente que real, uma vez que a suposta "decisão autônoma" da clientela estaria $a$ priori formatada pelas informações preconcebidas de profissionais ou pelas diretrizes das mencionadas Políticas Públicas Saudáveis.

Com a ampliação do objeto de intervenção na Nova Promoção à Saúde todos passam a ser, de alguma maneira, vítimas das políticas contemporâneas de prevenção (Petersen \& Lupton, 1996). É possível afirmar, com Caplan, que parte importante dos projetos de promoção à saúde tem dificuldade para superar o enfoque behaviorista e mantém o foco de sua atenção para ações voltadas para a regulação da vida social e para a criação de critérios que delimitem o sentido do viver saudável. A autonomia possível é, quase sempre, uma autonomia regulada uma vez que os indivíduos tendem a seguir regras e normas concebidas por expertos e pelos parâmetros construídos pelas Políticas Públicas Saudáveis.

O que se observa é que, apesar da centralidade do discurso preconizando a ampliação da autonomia do sujeito e de empowerment, muitas das narrativas de progresso que suportam as estratégias da Nova Saúde Pública deixam intocadas as discussões sobre as relações desiguais de poder na relação entre especialistas e não-especialistas, populações dos países ricos "desenvolvidos" e populações dos países pobres "em desenvolvimento", homens e mulheres, e heterossexuais e homossexuais masculinos e lésbicas (Petersen \& Lupton, 1996).

Em um mundo global onde amplia-se as ameaças socio-ambientais - vide o terrorismo 
praticado por grupos civis e por Estados Nacionais -, torna-se confortável pensar que a ação individual reduz as chances de uma morte precoce. A sensação de controle do indivíduo sobre o processo saúde-doença pode contribuir, de passagem, para justificar o argumento de que é possível assegurar a saúde sem que seja necessário realizar transformações no modo de produção vigente, nas relações sociais e (ou) de governantes (Tesh, 1988).

A seguir, procuro, pela análise da categoria empowerment, avançar um pouco mais na análise dessas questões.

\section{Promoção à saúde e empowerment}

Em trabalho recente descrevi e analisei as variantes desta categoria/estratégia (Carvalho, 2002; 2004), destacando de início que a categoria empowerment tem muito a oferecer para a promoção da saúde afirmando, contudo, que alguma precaução se faz necessária antes que esta noção seja abraçada entusiasticamente como um objetivo central às práticas sanitárias.

A promoção da saúde envolve escolha e, como tal, não se coloca na esfera do conhecimento científico, mas na esfera dos valores vinculando-se a processos que não se expressam de maneira precisa e facilmente mensurável. Esta característica da promoção explica, em parte, a centralidade que categorias como empowerment vêm assumindo uma vez que ele facilita o diálogo transdiciplinar e incorporações de temáticas como a diferença, a subjetividade e a singularidade de indivíduo e coletivos (Czeresnia, 1999).

Distintas concepções sobre o que é empowerment e o conflito de interesses que elas ensejam vêm gerando distorções no uso deste princípio/estratégia (Rissel, 1994). Relatei, na ocasião, a existência de duas abordagens principais do empowerment: o enfoque psicológico e o enfoque comunitário. Na diferenciação dessas variantes encontram-se múltiplas dimensões da categoria "poder", em que convivem dimensões criativas e instituintes da ação política e dimensões que reforçam o controle e a regulação do social: o poder que é opressão e, ao mesmo tempo, produção e potência liberadora.

A imagem do indivíduo anunciada pelo enfoque psicológico do empowerment é a de uma pessoa comedida, independente e autoconfiante, capaz de comportar-se de uma determinada maneira e de influenciar o seu meio e atuar de acordo com abstratos princípios de justiça e de equilíbrio (Riger, 1993). Dessa representação deriva a formulação de estratégias que têm como objetivo fortalecer a auto-estima e a capacidade de adaptação ao meio e desenvolver mecanismos de auto-ajuda e de solidariedade. Dentre essas, destacam-se práticas de educação para a saúde que pretendem contribuir para a formação da "consciência sanitária" do indivíduo, objetivando manter a harmonia e uma relação saudável dele com o seu meio externo. Apelase, aqui, para um esforço pedagógico sistemático e permanente, envolvendo técnicas focais e de marketing social que lembram estratégias.

Apontei, na ocasião, os limites desta perspectiva para um pensamento voltado para a transformação social e a produção da saúde, ao sugerir que o empowerment psicológico contribui, no máximo, para produzir uma autonomia regulada, uma espécie de Cogito empowerment, ergo sum empowered, no qual o sentimento de poder poderia criar a ilusão da existência efetiva de poder por parte dos indivíduos (Weissberg, 1999).

$\mathrm{Na}$ ordem capitalista atual, a utilização pouco rigorosa - ou motivada politicamente interessada - da categoria empowerment pode servir de justificativa para a diminuição e o retrocesso na prestação de serviços sociais e de saúde em tempos de conservadorismo fiscal. Nos Estados Unidos, por exemplo, políticas conservadoras vêm combinando as noções de empowerment e risco com a ideologia política da responsabilidade pessoal para sugerir que as pessoas, individualmente e através de estruturas de mediação como as igrejas e as associações voluntárias, devem contar consigo antes de recorrer a serviços prestados por instituições estatais (Riger, 1993; Robertson \& Minkler, 1994).

Visando a superações das mencionadas limitações, alguns teóricos da Nova Promoção à Saúde procuram nos trabalhos de Paulo Freire e Saul Alinsky a inspiração para a formulação de uma concepção alternativa que aqui denomino de empowerment comunitário. Central a este conceito é a afirmação de que processos de empowerment implicam, quase sempre, a disputa pelo controle de recursos e na redistribuição de poder.

Essa concepção não nega, mas antes o contrário, conteúdos do empowerment psicológico no momento em que propõe um conceito no qual conviva a noção de determinismo social e a de agenciamento humano a partir da compreensão de que as macroestruturas influen- 
ciam e condicionam o cotidiano dos indivíduos e estes conformam as macroestruturas. Isto pode ser observado no campo da saúde quando constatamos que se muitos estudos epidemiológicos demonstram o papel da pobreza e de outros fatores sociais, políticos e econômicos na influência do status de saúde individual, é igualmente verdade, por outro lado, que os indivíduos têm sido capazes de moldar o contexto social em que vivem afetando, conseqüentemente, a saúde do coletivo.

$\mathrm{O}$ "empowerment comunitário" suscita a elaboração de estratégias que procurem promover a participação visando ao aumento do controle sobre a vida por parte de indivíduos e comunidades, a eficácia política, uma maior justiça social e a melhoria da qualidade de vida. Espera-se, como resultado, o aumento da capacidade dos indivíduos e coletivos para definirem, analisarem e atuarem sobre seus próprios problemas. Mais do que repassar informações e induzir determinados comportamentos, esta estratégia sugere que as pessoas e coletivos sejam apoiados no processo de reflexão sobre os problemas postos pela vida em sociedade, procurando contribuir para a tomada de decisões, o desenvolvimento da consciência crítica e o aumento da capacidade de intervenção sobre a realidade (Raerbum \& Rootman, 1998; Hills, 2000).

O empowerment transforma- se, nesta proposta, em um conceito e estratégia política que se contrapõe a propostas de gestão e regulação do social que sustentam projetos que contribuem para a manutenção da ordem social iníqua e injusta.

\section{Considerações finais}

A análise crítica levada a efeito conclui que o ideário da promoção à saúde pode contribuir para a ruptura entre as velhas e novas práticas em saúde, fornecer elementos para transformação do status quo sanitário e para a produção de sujeitos autônomos e socialmente solidários. Contraditoriamente os seus enunciados teóricos e indicações estratégicas - aparentemente inovadoras, radicais e suficientes para efetivas mudanças no campo da Saúde - podem encobrir uma abordagem funcionalista e conservadora que favoreça o status quo e reforce a hegemonia do ideário da ordem neoliberal.

Considero, em consonância com a primeira perspectiva, que a promoção à saúde é uma abordagem que tem contribuído para a renovação do pensamento sanitário contemporâneo buscando contrapor-se ao modelo biomédico, hospitalocêntrico e curativo que dominou o pensamento sanitário nas últimas décadas. Resgata de alguma maneira o papel dos determinantes sociais no processo saúde/doença, presente no ideário da medicina social do século 19, defendendo ações que levem em conta a importância da articulação intersetorial, das abordagens interdisciplinares e da participação social.

Ao considerar todos os fatores causais da saúde e doença esta abordagem amplia o alcance das atividades de promoção à saúde para além dos parâmetros tradicionais da saúde pública e da prevenção da doença. Realiza, em paralelo, uma síntese inovadora de conceitos originários de campos disciplinares como a sociologia, a psicologia, a ciência política, a economia, a epidemiologia e a ecologia introduzindo novas idéias, linguagens e conceitos sobre a saúde e sobre a maneira de produzi-la.

Apesar das possibilidades apontadas é possível afirmar, a partir de Stevenson \& Burke (1991), que os fundamentos básicos da promoção à saúde estão em total acordo com o caráter "progressista", "democrático" e "humanitário" dos novos movimentos sociais e, ao mesmo tempo, com os valores da democracia neoliberal das sociedades na qual muitos destes movimentos emergiram.

É significativo que a Nova Promoção à Saúde seja freqüentemente descrita como um "movimento" para a mudança e que seja pautada, em grande parte, pela linguagem dos novos movimentos sociais usando termos como "auto-ajuda", "eqüidade", "colaboração", "empowerment", "participação", "controle comunitário". Esta linguagem de conceitos como "prevenção de riscos", "políticas públicas e hábitos saudáveis" tem vasto apelo e o seu uso tem sido um importante meio pelo qual a Nova Promoção à Saúde tem alcançado um amplo suporte, apesar de se manter fortemente vinculada aos objetivos oficiais. Ela serve, também, para mascarar mudanças de relação de poder que envolva, em particular, a redefinição dos direitos da cidadania.

Ou seja, a promoção à saúde não é necessariamente um projeto libertário e voltado para a justiça social. A análise da utilização do conceito de risco e de empowerment junto deste ideário constata a possibilidade de que suas intervenções e conceitos venham reforçar estraté- 
gias voltadas para a regulação e a vigilância sobre os corpos sociais e individuais com profundas implicações políticas, morais e sociais de algumas de suas estratégias.

Explicando estas contradições menciono, entre outros, os seguintes fatores explicativos:

- incorporação pragmática de categorias procedentes de distintos saberes sem o rigor teórico/conceitual que aponte com precisão o significado do afirmado, gerando uma imprecisão que dificulta a implementação de estratégias claras de soerguimento da saúde pública, uma vez que, em nome do consenso, a Promoção à Saúde pode significar "tudo para todos" (Bunton \& MacDonald, 1992a;b; Caplan, 1993);

- a presença quase sempre marginal de temas como conflito de classes e a relação capitalismo e saúde, despolitizando o debate e sinalizando para a defesa de uma sociedade socialmente integrada e harmônica onde os indivíduos são induzidos a mudar seus hábitos de vida para terem saúde;

- a distância dos enunciados teóricos, que destacam o papel dos fatores sociais e ambientais na determinação da saúde e parte das estratégias da Nova Promoção à Saúde que priorizam a intervenção sobre a "doença fatores biológicos e comportamentais" (Baum \& Sanders, 1995).
Apesar dos problemas apontados, é fundamental assinalar que o ideário da Nova Promoção à Saúde sintetiza parcela importante dos projetos igualitários e democratizantes em saúde no Canadá e vem trazendo contribuições relevantes para a reforma sanitária brasileira (Minayo et al., 2000; Czeresnia \& Freitas (org.), 2003). No estudo em questão coloquei em relevo a utilidade de conceitos como "empowerment" e "participação comunitária" para um projeto que almeje a transformação do status quo sócio-sanitário no Brasil (Rissel, 1994) afirmando, entre outros, o valor das intervenções sobre os hábitos de vida saudável sempre que se levasse em conta que a definição do "saudável" e do "risco" é uma construção histórica e social.

Concluo afirmando que para a realidade brasileira a incorporação das premissas e estratégias de promoção à saúde no SUS deva ter como parâmetro a necessidade se superarmos as raízes estruturais da iniqüidade na saúde, o que passa, necessariamente, por dar respostas aos desafios de: a) garantir o acesso a bens e serviços de saúde de qualidade; b) produção de sujeitos autônomos e socialmente responsáveis e c) contribuir para a democratização do poder político.

\section{Referências bibliográficas}

Almeida Filho N \& Rouquayrol MZ 1992. Introdução à epidemiologia moderna. COOPMED-APCE-Abrasco. Belo Horizonte-Salvador-Rio de Janeiro

Baum F \& Sanders D 1995. Can health promotion and primary health care achieve health for all without a return to their more radical agenda? Health Promotion International 10(2):149-160.

Bunton R \& MacDonald G 1992a. Introduction, pp. 6-22. In R Bunton \& G MacDonald (eds.). Health promotion: disciplines and diversity. Routledge, Nova York.

Bunton R \& MacDonald G 1992b. Health promotion: discipline or disciplines?, pp. 6-22. In R Bunton \& G MacDonald (eds.).Health promotion: disciplines and diversity. Routledge, Nova York.

Buss PM 2000. Promoção da Saúde e qualidade de vida. Ciência \& Saúde Coletiva 5(1):163-178

Caplan R 1993. The importance of social theory for health promotion: from description to reflexivity. Health Promotion International 8(2):147-157

Carvalho AI 1996. Da saúde pública às políticas saudáveis: saúde e cidadania na pós-modernidade. Ciência é Saúde coletiva 1(1):104-121. 
Carvalho SR 2002. Saúde coletiva e promoção à saúde: Uma reflexão sobre o tema do sujeito e da mudança. Tese de doutorado. Faculdade de Ciências Médicas, Universidade Estadual de Campinas, Campinas.

Carvalho SR 2004. Os múltiplos sentidos da categoria "empowerment" no Projeto de Promoção à Saúde. In Cadernos de Saúde Pública. (No prelo).

Castel R 1991. From dangeroussness to risk, pp. 281-298. In G Burchell, C Gordon \& P Miller (eds.). The Foucault Effect: studies in Governamentality. HarversterWheatsheaf, Londres.

Castiel LD 2003. Dédalo e os dédalos: identidade cultural, subjetividade e os riscos saúde, pp. 79-96. In D Czeresnia (org). Promoção da Saúde: conceitos, reflexões, tendência. Fiocruz, Rio de Janeiro

Crawford R 1977. You are dangerous to your health: the ideology and politics of victim blaming. International Journal of Health Services 7(4):663-680.

Czeresnia D 1999. The concept of health and the difference between prevention and promotion. Ciência \& Saúde Coletiva 15(4):701-710.

Czeresnia D \& Freitas CM (orgs.) 2003. Promoção da saúde: conceitos, reflexões, tendência. Fiocruz, Rio de Janeiro.

Guattari F \& Rolnik S1986. Micropolitica: cartografias do desejo. Editora Vozes, Petrópolis.

Hancock T 1985. Beyond health care: from public health policy to healthy public policy. Canadian Journal of Public Health (76):supplement 1.

Hills M 2000. Workshop for teachers of Health Promotion. VI Brazilian Congress on Collective Health. AbrascoENSP-CPHA, Rio de Janeiro.

Hyndman B 1998. The evolution of health promotion. Health promotion in action: a review of the effectiveness of health promotion strategies. Centre for Health Promotion/ParticipACTION. Section 1-3, Toronto.

Labonte R 1993. Health promotion and empowerment: practice frameworks. Centre for Health Promotion, Toronto.

Labonte R \& Penfold S 1981. Canadian perspectives in health promotion: a critique. Health Education 19(3/4):4-9.

Lalonde M 1974. A new perspective on the health of Canadians: a working document: health and Welfare Canada. Ottawa.

Lupton D 1999. Risk. Routlege, Nova York.

Mendes EV (org.) 1993. Distrito Sanitário: o processo social da mudança das práticas sanitárias do Sistema Único de Saúde. Hucitec, São Paulo.
Minayo MCS, Hartz ZMA \& Buss PM 2000. Qualidade de vida e saúde: um debate necessário. Ciência \& Saúde coletiva 5(1):7-18.

PAHO 1996. Health promotion: an anthology. Scientific Publication 557. Pan American Health Organization, Washington.

Petersen A 1997. Risk, governance and the New Public Health, pp. 188-306. In A Petersen \& R Bunton (eds.) Foucault, health and medicine. Routledge, Londres.

Petersen A \& Lupton D 1996. The New Public Health: health and self in the age of risk. Sage Publications Ltd., Londres.

Raerburn J \& Rootman I 1998. People-centred health promotion. John Wiley \& Sons, Toronto, ON.

Riger S 1993. What's wrong with empowement. American Journal of Community Psychology 21: 279-292.

Rissel C 1994. Empowerment: the holy grail of health promotion? Health Promotion International 9(1):39-47.

Robertson A \& Minkler M 1994. New health promotion movement: a critical examination. Health Education Quarterly 21(3):295-312.

Stevenson HM \& Burke M 1993. Bureaucratic logic in new social movement clothing: the limits of Health promotion research. Canadian Journal of Public Health 83 (Supplement 1), S47-S53.

Teixeira CF, Paim J \& Vilaboas A 1998. SUS: modelos assistenciais e vigilância da Saúde. Informe Epidemiológico do SUS, vol. VII (2), CENEPI/MS, Brasília.

Tesh S 1988. Hidden arguments: political ideology and disease prevention policy. Rutgers University Press, New Brunswick.

Westfall MF 2000. O Movimento Cidades/Municípios Saudáveis: um compromisso com a qualidade de vida. Ciência \& Saúde Coletiva 5(1):39-52.

WHO (World Health Organization) 1984. Health Promotion: a discussion document on the concept and principles of Health promotion. Health Promotion 1:73-78.

WHO (World Health Organization) 1986. Ottawa Charter for Health Promotion - Health Promotion (HPR). Disponível em <http://www.who.int/hpr/docs/ottawa.html>

Weissberg R 1999. The politics of empowerment. Praeger Publishers. Westport CT.

Artigo apresentando em 26/4/2004

Aprovado em 9/7/2004

Versão final apresentada em 12/7/2004 